\title{
AS INSCRIÇÕES DE SI DA POPULAÇÃO DE RUA NO JORNAL BOCA DE RUA
}

\author{
Arthur Walber Viana ${ }^{1}$ \\ Universidade Federal do Rio Grande do Sul (UFRGS) \\ arthurwalber@hotmail.com \\ Valdir Jose Morigi ${ }^{2}$ \\ Universidade Federal do Rio Grande do Sul (UFRGS) \\ valdir.morigi@gmail.com
}

\begin{abstract}
Resumo
Como a população de rua inscreve a si própria na narrativa do Jornal Boca de Rua: é essa, de maneira sucinta, a questão que o artigo buscará desvendar. Por ser uma publicação na qual as pessoas em situação de rua são os sujeitos criativos por trás dos textos, intriga-nos a maneira como usam esta relativa liberdade de "definir a si". Efetuaremos um estudo actancial: atentaremos ao que moradoras e moradores de rua fazem nos textos; que linguagem usam; com quem e com o que se relacionam. Apesar de qualquer limite imposto, sintático, sociopolítico ou econômico, há no Boca de Rua um grito contra as impossibilidades que esmagam estas vidas precárias, símbolos máximos da decadência do capitalismo neoliberal mundial: o jornal mostra-se um lugar de memória, espaço para a inscrição no mundo de vidas singulares e dignas de lembrança.
\end{abstract}

Palavras-chave: Jornal Boca de Rua. Moradores de rua. Relato de si. Actantes. Análise da narrativa.

\section{SELF INSCRIPTION OF HOMELESS PEOPLE IN "BOCA DE RUA"}

\begin{abstract}
How homeless people inscribe themselves in the narrative of the newspaper "Boca de Rua" (meaning "Street Mouth"): in a succinct way, this is the question that the article will seek to unravel. Because it is a publication in which homeless people are the creative subjects behind the texts, it intrigues us how they use this relative freedom to "define themselves". We will carry out an actancial study, paying attention to what homeless characters do in the texts; what language do they use; with whom and with what they relate to. In spite of any imposed, syntactic, socio-political or economic limit, there is in Boca de Rua a cry against the impossibilities that crush these precarious lives, the maximum symbols of the decadence of world neoliberal capitalism: the newspaper is a place of memory, space for inscription in the world of unique lives and worthy of remembrance.
\end{abstract}

Keywords: Boca de Rua newspaper. Homeless people. Self inscription. Actants. Narrative analysis.

\footnotetext{
1 Mestrando do Programa de Pós-Graduação em Comunicação e Informação da UFRGS (Universidade Federal do Rio Grande do Sul).

${ }^{2}$ Dr. em Sociologia e Professor Titular do Departamento de Ciências da Informação e do Programa de PósGraduação em Comunicação e Informação da UFRGS (Universidade Federal do Rio Grande do Sul), Pósdoutorando em Memória Social (PPGMS/UNIRIO), com bolsa do CNPq.
} 


\section{INTRODUÇÃO}

O Jornal Boca de Rua é o jornal da população de rua de Porto Alegre, feito [quase] ${ }^{3}$ de início a fim - da reunião de pauta que decide os assuntos abordados à venda dos exemplares nas esquinas - por elas e por eles. Talvez por isso as reportagens produzidas se dirijam sempre a temas como as violências policial, urbana, contra a mulher, do Estado (representada na deficiência ou completa ausência de programas sociais voltados a esta população); agressões extremamente próximas de quem habita calçadas, praças e viadutos das cidades brasileiras e, justamente por isso, assuntos recorrentes na publicação. Por isso, para além da "coisa em si", a presença física no tempo e no espaço materializada nas 16 páginas em formato tabloide, a diferença que enfatizamos no Jornal Boca de Rua está nos seus enunciados: a unicidade do periódico surge da sua maneira de representar o mundo ou, mais precisamente, do local de onde representa o mundo, que acaba por constituir o "seu" mundo, assim, possessivo, universo único e intransferível que pertence àquele grupo de fazedores-de-um-jornal e, posto ao mundo, um outro, é roubado por este e por tantos, que o preencherão de sentidos - tal qual este artigo.

Nas reportagens, para além de objeto de um texto, vítima de uma tragédia a ser contada, as pessoas em situação de rua são escritoras, os sujeitos criativos por trás dos relatos - no caso, relatos de si (BUTLER, 2015): no Boca de Rua, a rua fala de si, ao seu modo e sobre o seu mundo. Um poder grande: a liberdade de se definir e inscrever a si mesmo na realidade social - e, no entanto, ainda que se assuma tal poder, o que buscamos é refletir sobre esta dita liberdade, em termos de dimensão e possibilidade. Portanto, a pergunta para a qual buscamos resposta é (e ela leva sempre a outras): como é construída a inscrição de si de moradoras e moradores de rua na narrativa do Jornal Boca de Rua? Como estas narrativas agem na construção das memórias desta população - e o que nos dizem tais memórias? Que relações com a cidade os relatos explicitam? Em termos mais amplos, que liberdade temos ao escrever, (re)criando mundos e a nós mesmos? E que liberdade têm estas pessoas que vivem constantemente a violência das ruas, do abandono, ao escrever ou não; ao existir?

Atrás de respostas, efetuaremos um estudo actancial (GREIMAS e FONTANILLE, 1993; LATOUR, 2012; LEMOS, 2013; SANTAELLA e CARDOSO, 2015). Voltaremos nossa atenção às ações efetuadas pelas pessoas em situação de rua inscritas no texto do jornal: o que fazem, que linguagem utilizam, que lugares frequentam; e também a como estes lugares se relacionam com elas e eles: a noção de actantes traz em si o descentramento do sujeito, levando

\footnotetext{
${ }^{3}$ Há edição; explicaremos adiante.
} 
em conta, para além da pessoa, as coisas, os lugares e os artefatos que também agem no desenrolar da narrativa, aquilo tudo o que faz e aquilo tudo que faz fazer. Inspiramo-nos também, entre outras e outros, na exploração dos limites representativos de nossas proposições, mesmo quando autorreferenciais, a partir de Butler (2011; 2015), Derrida $(1995,2008)$ e Deleuze (1998). Somamos a estas perspectivas a abordagem de Hall et al (1978) a respeito das Teorias do Jornalismo.

Para a análise prática, escolhemos a matéria de capa da edição de número 62 do jornal, do ano de 2017. A escolha se justifica por ser este artigo recorte da dissertação de mestrado do autor; queremos aqui ampliar o seu alcance e propor debates a respeito da temática, convencidos da relevância social do projeto do Jornal Boca de Rua, sobre o qual falaremos abaixo.

\section{SOBRE O JORNAL BOCA DE RUA}

Começaremos, antes de um mergulho teórico, por uma contextualização a respeito do nosso objeto de estudo: afinal, houve sempre o objeto, antes de qualquer pretensão científica que agora colocamos sobre ele. O jornal Boca de Rua existe há 17 anos e é produzido em Porto Alegre, Rio Grande do Sul, Brasil, sob a coordenação da Alice (Agência Livre para Informação, Cidadania e Educação) ${ }^{4}$. No periódico, que é impresso trimestralmente e tem tiragem de oito mil exemplares, moradoras e moradores de rua são responsáveis por todas as etapas do fazer jornalístico, à exceção da impressão, diagramação e edição, quando esta é necessária, em especial devido a questões de espaço - tratamos, afinal, de um meio impresso de área disponível limitada. Da definição de pautas à apuração das reportagens, dos debates como que em uma redação de jornal às fotografias, da escrita dos textos à venda dos exemplares em sinaleiras e esquinas de Porto Alegre, quase tudo depende exclusivamente das pessoas em situação de rua evolvidas no projeto - que são hoje em torno de 30, embora o número tenha variado ao longo dos anos. Foram impressos, desde 2001 e até janeiro de 2019, momento de finalização deste texto, 71 números do jornal.

As reuniões são semanais e nelas, além do debate jornalístico em si, conversa-se abertamente a respeito de questões de convivência do grupo (existem regras a serem seguidas cujo desrespeito pode acarretar em exclusão: entre elas, não roubar pertences dos colegas, não dormir nas reuniões, não vender os jornais sob o efeito de drogas, etc.). Monta-se também uma

\footnotetext{
${ }^{4}$ Alice é uma organização sem fins lucrativos surgida em 1999. Seu intuito é defender o direito universal à comunicação, à cultura e à arte. Disponível em: http://www.alice.org.br/quem-somos/. Acesso em: 20/03/2018.
} 
agenda para o grupo, com a determinação de responsáveis para cada compromisso, já que o jornal com frequência é convidado a participar de entrevistas em programas de rádio e televisão, em palestras em universidades e outra série de atividades. O trabalho de Alles (2010) traz um relato detalhado do funcionamento interno do Boca de Rua e foi de grande valia para esta pesquisa: a autora, em um duplo papel, posto que era também voluntária no jornal, realiza uma observação participante na rotina do grupo, trazendo uma riqueza de detalhes sobre o seu cotidiano que explicitam muitas das tensões que o fazem ser tal é.

Não alargar demais o número de moradoras e moradores de rua envolvidos, o que exigiria um número maior de apoiadores que participassem do processo (existem voluntários que ajudam nas reuniões e no desenvolvimento das pautas), mostra ter também uma razão econômica: o dinheiro da venda dos exemplares (dois reais) é destinado à própria vendedora ou vendedor, e cada uma recebe uma cota semanal de exemplares do jornal para comercializar. Assim, o Boca de Rua efetiva-se como uma prática transformadora tanto no campo simbólico, ao enfrentar representações sociais postas sobre a população de rua já bastante estáticas, como no campo socioeconômico, ao possibilitar uma complementação de renda e trabalho a seus integrantes. Para se tornar um membro efetivo, é necessário acompanhar três reuniões sem receber jornais, como que para mostrar um real interesse no projeto; a partir da quarta reunião, recebe-se um crachá do jornal e a cota semanal de exemplares.

Na própria definição em seu blog ${ }^{5}$, o Boca de Rua mostra que não produz discursos sobre o Outro 6 ; ele é o discurso do Outro (ou um dos, não devemos negar a variabilidade): “A gente vive o que diz. Sente que o diz. É um jornal vivido"7. Ignoremos, por esta ocasião, as problemáticas que surgem relativas à prática jornalística, se seus relatos seguem os ilusórios critérios de objetividade, a pirâmide invertida ou a imparcialidade: importa-nos mais entender os conteúdos que compõe esta narrativa e suas formas de apresentação: afinal, há uma opção pelo uso de ferramentas do discurso jornalístico, o que não é mero acaso; o código eleito para inscrever os relatos de realidade da população de rua é o do jornalismo, e tal premissa pressupõe verdade no que está escrito.

\footnotetext{
${ }^{5}$ Disponível em: https://jornalbocaderua.wordpress.com/.

${ }^{6}$ Tomamos por Outro os seres aos quais não reconhecemos a precariedade (LÉVINAS, 1997a; 1997b; BUTLER, 2011).

${ }^{7}$ Disponível em: https://jornalbocaderua.wordpress.com/sobre-nos/. Acesso em: 20/03/2018.
} 


\section{A VIOLÊNCIA DA DEFINIÇÃO: MULTIPLICIDADES SILENCIADAS}

O que buscamos é entender como se dão as inscrições de si da população de rua nos textos escritos exatamente por elas e por eles. Que memórias se prolongam nas páginas do Boca de Rua? Que inscrições são dignas de serem postas ao papel e efetuam-se como rastros de algo a ser lembrado? Afinal, que liberdade temos para falar, ainda que de nós mesmos? Para responder estas intrincadas perguntas, o caminho é tortuoso, sabemos: primeiro, veremos que algo sobre mim já foi sempre falado, e não partimos do zero; segundo, as próprias condições a respeito do que e de como posso falar já estão postas, a regra - seja a da linguagem que me é ensinada e acessível, seja dos meios disponíveis, seja de protocolos sociais - já está posta, sem consulta prévia (embora mutável); terceiro, partindo exatamente desta mutação possível: há sempre abertura para algo mais, para a diferenciação, para o movimento; portanto, as multiplicidades silenciadas com a violência de uma definição reagem, escapando por infinitas linhas de fuga rizomáticas (DELEUZE; GUATARRI, 1995a), impondo-nos, por fim, uma ética da mobilidade e da alteridade. Vamos por partes:

\subsection{Definições primárias}

Estamos sempre em relação, em uma rede de interdependência (ELIAS, 2001). Pronto, destituímos o Eu de sua majestade: aqui estamos como resultado de uma série de desencontros e encontros anteriores, dos agenciamentos maquínicos (DELEUZE, GUATARRI, 1995b), e mesmo nosso discurso é produto de tudo com o que já fomos atingidos ou atingimos em redes que circulam desde um tempo imemorável e de onde nossas condições de pensar e discursar procedem: “Quando nascemos os discursos já estão em processo e nós é que entramos nesse processo. Eles não se originam em nós” (ORLANDI, 1999, p.35). Negamos a totalidade, uma identidade pronta e fixa, livre da influência exterior, e eis a angústia ontológica: somos sempre e apenas o mo(vi)mento, a relação, algo adiante. E, no fluxo, alguma definição já foi sempre posta sobre mim - o embarque é em um veículo acelerado.

Em meio aos choques, fortalecem-se alguns pontos ao passo que outros perdem força e quase somem em meio à fumaça dos rastros, e algumas vozes encontrarão ecos, atingindo distância sempre maior. O jornalismo, um entre vários discursos possíveis, possui um estatuto privilegiado dentro da cultura (BIRD; DARNDENNE, 1999) - o que não significa que possa manipular livremente as informações da vida social. Muitas vezes oprimidos por limitações de tempo e condições laborais adversas, jornalistas recorrem a simplificações que permitem que 
vençam a hora de fechamento (TRAQUINA, 2004): entram aí a construção do relato de acordo com a pirâmide invertida - responder objetivamente o que, quem, quando, onde e por que - e a procura por fontes já legitimadas e preparadas para lidar com a mídia - são estas, aliás, que Hall et al (1978) denominam definidores primários, porta-vozes de discursos oficiais e institucionalizados que já ostentam posição privilegiada no meio social e são constantemente abordados pelo jornalismo para que publicizem suas visões dos acontecimentos. Preparadas e interessadas, encontram aí meio eficaz para reforçar interesses privados, fantasiando-os de interesses coletivos. Estes discursos constroem "consensos" (aparentes) no meio social a respeito do que deve pautar o debate público e como este debate deve transcorrer - ou seja, que olhar deve ser dado aos acontecimentos eleitos como merecedores de atenção. São pontos dominantes em uma rede em permanente disputa, na qual as perspectivas de mundo buscam legitimação e sobrevivência; assim, qualquer outro discurso, antes de ser o que quer que pretenda inicialmente ser, deverá confrontar estes falsos consensos a respeito da realidade social para efetivar-se. Será (e é) em função destes definidores primários (HALL et al, 1978).

Fenômeno recente, a comunicação interpessoal descentralizada, que corre veloz por aplicativos de mensagem instantânea como o WhatsApp, coloca-se como um novo paradigma para este conceito; porém, uma análise cuidadosa mostrará que também as mensagens que circulam por estas redes agem em lógica semelhante: pautam o debate público e definem os termos deste debate. Recebidas em grupos afetivos e muitas vezes desapegadas de valores éticos ou factuais, parecem mesmo aprofundar os riscos de definições primárias: descontextualizadas, fortalecem uma única visão de mundo; o contraditório e a diferença passam a ser combatidos a partir destas definições prévias e de uma compreensão dicotômica da realidade, separando-a de maneira ingênua entre critérios de "certo" ou "errado".

\subsection{E nem de mim posso falar livremente?}

De início, pensa-se ser sempre uma questão de escolha individual - e de certo modo é: dizer de um jeito é não dizer de nenhum outro e apenas eu controlo o que é por mim pronunciado ou escrito ou digitado. Porém, isso pode nos levar a alguns equívocos, como a crença de que o dito e o entendido serão o mesmo, fenômeno único, acreditando-se ter controle da totalidade do processo comunicacional. $\mathrm{O} \mathrm{Eu}$, contudo, “[...] não é primeiro e suficiente na ordem da fala senão na medida em que envolve significações que devem ser desenvolvidas por si mesmas na

\footnotetext{
${ }^{8}$ Para aprofundamento, Viana e Morigi (2018b).
} 
ordem da língua" (DELEUZE, 1998, p.19). Outro desentendimento reside na crença de que as escolhas, uma vez que feitas por nós, não são afetadas por uma série de relações, o que as impede de serem livres, e de que todo o não-dito gerado por estas escolhas está automaticamente excluído de qualquer análise, imperceptível. Não notaríamos, assim fosse, que a palavra eleita a ser escrita ou dita ou gritada é resultado de disputas por poder, choques que moldam nossa escolha e nos fazem optar por este signo no lugar daquele, ou definir aquele assunto como o mais urgente para o momento. Passar-nos-ia despercebida a chance de qualquer coisa ser algo diferente do que da maneira como nos é oferecida.

Assim que, postas intencionalmente sobre um jornal, as representações serão tomadas pelo consumidor, num constante roubo de símbolos: concordamos de início que os leitores significam o que leem e o jornal significa o significado que recebe. Qualquer pretensa centralidade do sujeito criador já se vê assim invadida, frente a ampla gama de possibilidades de significações a ser recebida por uma mesma mensagem. No entanto, há também o dito, o pretendido; os signos estão mesmo ali, postos à análise de quem se arriscar abstrair deles algum sentido, e não podemos apenas atirar a liberdade de criar mundos ao outro extremo, o do receptor, como se ali a liberdade para tanto fosse absoluta. O preenchimento, perceba, nunca é livre como se imagina ser a folha branca no exercício de desenho dado à criança: há o limite do que está escrito ou dito ou do que é visível e sensível (que por sua vez limita-se a questões linguísticas e simbólicas do que é sabido representar); há o limite de quem lê ou escuta ou vê ou sente de alguma forma; e há apenas as possibilidades dadas por determinada plataforma em que as representações são despejadas. Há desejo e frustração em um extremo e no outro, e no meio também. O sentido está no encontro (DELEUZE, 1998) e mesmo a "nossa" linguagem não nos pertence, é social: parece não haver espaço para um Eu livre de Outro, um espaço seguro para constituir-nos sozinhos, um Eu separado das condições sociais de seu surgimento (BUTLER, 2015).

\subsection{Multiplicidades silenciadas e reencontradas: a ética do Rosto}

Qualquer definição é tentativa de parar o movimento do ser: uma violência. O objeto deste estudo, ou seja, a inscrição de si, não pode ser encarada como algo essencial, possível de ser definida com a simplicidade de um sou isso porque digo que sou. Posso afirmar-me laranja e não vermelho, e ser laranja é exatamente o que me impede de ser vermelho; ainda assim, há vermelho em mim e posso dizer, talvez, que sou amarelo demais para ser vermelho, o que faz de mim laranja, apesar do vermelho que também me habita. Sou, e somos, nós e as coisas e as 
representações todas, resultados infindáveis de instaurações, momentos que se constroem uns sobre os outros, e que às vezes desabam apenas para seguir sendo construídos de outra maneira, em suas eternas linhas de fuga rizomáticas (DELEUZE; GUATTARI, 1995a). Contudo, não negamos a identidade, uma vez que aqui posta: apenas reafirmamos que, enquanto estabilizações momentâneas, é preciso compreender sua eterna mobilidade.

Esta é a violência que definidores primários impõem em suas narrativas, muitas vezes descontextualizadas, colocando o Outro sob as categorias do exótico ou do grotesco (SODRÉ, 2004; LAGO, 2010): falar é sempre a escolha de uma palavra no lugar de outra; representar é também silenciar: é fechar todas as outras possibilidades que poderiam vir a ser e não foram (ORLANDI, 1992). Sempre se poderia dizer algo de maneira diferente ou outra coisa um tanto diversa de um mesmo algo, nossas percepções variam sempre de acordo com as condições de acesso ao que é percebido; as "coisas" contém uma multiplicidade que extrapola os desejos narcisistas de verdade do Eu Uno. É a abertura eterna do texto (DERRIDA, 2008), o incessante vir-a-ser que nos impede de parar e ser, simplesmente.

Se compreendo que não posso sequer definir livremente quem sou, encontrarei agora paciência para com o Outro que também angustia-se perante a ausência de definições sobre si. Ao nos perguntarem "Quem és?" a resposta comum é um nome, o nosso, embora isso pouco ou nada acrescente na maior parte dos casos, e não respondêssemos pelo nome talvez retrucaríamos sempre definições por demais variadas, tão diversas quanto estes papéis múltiplos que exercemos ao longo da vida. Tal resposta resta então sem fechamento, jamais satisfeita, aberta ao eterno (BUTLER, 2015). Em tal abertura encontramos nada além da precariedade alheia, a humanidade: veremos ali um Rosto (LÉVINAS, 1997a; 1997b; BUTLER, 2011): é o Outro me impondo sua miséria, da qual não posso me eximir, e não haverá interioridade na qual possa encontrar esconderijo: o barbarismo da alteridade (LÉVINAS, 1997b). O Outro ataca a soberania egoísta do $\mathrm{Eu}$, que, acuado, ergue muros ao ver sua pretensa estabilidade comprometida. Apenas a compreensão da fragilidade do binarismo expresso em "certos e errados", que inconvenientemente impõem falsos consensos à sociedade, e da mobilidade das (des)conexões que poderá nos livrar, ao menos em parte, deste idealismo estático. A diferença se impõe sempre, motor que coloca o mundo em movimento, forçando o Eu a manejar o múltiplo, ainda que contra sua vontade. 


\section{ESTUDO ACTANCIAL: SINGULARIDADES QUE MERECEM MEMÓRIA}

Vemos na narrativa uma ordem performática (BARTHES, 1976): é ela uma mediadora fundamental na interpretação de si (BARBOSA, 2003), com potencial de reconstrução do self ao performar a experiência. Assim, a prática narrativa mostra-se uma interessante maneira de contrapor representações já construídas sobre si a partir de outros discursos e, por isso, ferramenta valiosa à população de rua, costumeiramente tão desvalorizada em relatos jornalísticos. Porém, mesmo que sempre intencionais, os relatos de si (ou de outros) inevitavelmente encontrarão barreiras ao seu querer dizer (BARTHES, 1976; DELEUZE, 1998; DERRIDA, 2008; BUTLER, 2011) - ou seja, escapam ao controle de um Eu Totalizador. Dependem das possibilidades de uma língua convencionada e ensinada; das possibilidades técnicas do meio e de quem o opera; e das relações diversas que construíram o relato, levandoo ao ponto de recepção, de onde se extrairá qualquer sentido. Enxergamos as narrativas como resultados das tensões, do choque de intenções e possibilidades que moldam a "coisa" sob análise: narrativa é relação.

Para escapar de definições essencialistas, focaremos o estudo na categoria dos actantes, que são, em resumo, tudo aquilo que produz diferença e põe em movimento, ou seja, faz o outro fazer (GREIMAS; FONTANILLE, 1993; LATOUR, 2012; LEMOS, 2013; SANTAELLA; CARDOSO, 2015), sejam coisas, artefatos, animais - humanos ou não. Tal visão compartilha a responsabilidade da ação, livrando-a da tutela de um sujeito ou de uma consciência: falamos, antes, do encontro de actantes - a arma, a mão, o medo, o discurso de ódio de um presidente , das possibilidades deste encontro ocorrer e do que decorre a partir dele. Assim que vamos primeiro observar o que fazem moradoras e moradores de rua no texto: ações, verbos, linguagem utilizada. Atentaremos também ao entorno, às relações: ver a cidade inscrita no papel; compreender quem são os "outros" desses estigmatizados como Outros maiúsculos. Por último, em uma leitura mais ampla e relativamente livre de métodos enclausurantes, praticaremos a errância em sua máxima potência, inspirados pela desconstrução de Derrida (1995; 2008) e pela (des)mitologia de Barthes (2012): queremos discernir os mitos que escorrem por frases e palavras e pontuações, que partem sempre e apenas daquilo expresso no texto e que, no entanto, indicam temas de fundo que se conectam a uma rede de discursos que nos antecede e ultrapassa, e que seguirá seu fluxo de conexões e desconexões, levando alguma significação sempre adiante.

Para tecer considerações práticas, selecionamos a matéria de capa da edição número 62, lembrando tratar aqui do recorte de uma dissertação de mestrado cujo escopo é mais amplo. 
Esta edição, relativa ao primeiro trimestre de 2017, traz como conteúdo principal o texto "Rita no coração", uma homenagem à integrante do Boca de Rua, Rita, que havia falecido no novembro anterior. Não poderemos aqui, o espaço é o limitador, apresentar a íntegra do texto analisado. Mostraremos, portanto, partes: as ações de Rita; do autor-narrador que escreve o texto; as relações estabelecidas com e pelo entorno, a cidade inscrita nas páginas do jornal.

Primeiro, uma breve descrição da matéria se faz necessária: ela trata da história de vida de Rita, integrante da equipe do Boca de Rua. Rita falecera dois meses antes da edição número 62 ir às ruas, vítima da tuberculose. O material aparece então como que uma homenagem à sua vida, como que em um obituário, singularizando-a e mostrando-a digna de lembrança. As ações atribuídas à Rita são ações singularizantes. Algumas, a fins de exemplificação: "Rita fechava os olhos quando falava"; "ela tinha uma grande família no jornal"; "ela era agitada, falava muito e às vezes gostava de recitar o poema 'Caminhos que se cruzam'”; “quase sempre estava acompanhada de Didi"; "Rita dividia tudo, sua comida preferida era arroz com gordurinha”; "tinha um gosto muito estranho, que era suco de maracujá e manga com sal"; "Rita armava um barraco porque não era de levar desaforo para casa"; "gostava de dar entrevistas".

Mais que apenas morar na rua - e é essa sempre a ação principal que lhes é imposta, alcunha máxima que as define, pesadamente: morar na rua, é esse o fazer que se é e que, por isso, precisa ser descentralizado, posto que a população de rua é (porque faz) muitas coisas mais -, Rita é poeta, vendedora, amiga, generosa, gosta de crianças mais que do "arroz com gordurinha". Há no texto uma especificação daquela existência, a de Rita, única e especial, por direito - como qualquer outra. São lembradas peculiaridades suas, hábitos como fechar os olhos para falar ou comer e beber coisas que os outros não costumam; o texto mostra que ela marcou vidas. Suas realizações não foram apagadas quando ela "fechou os olhos e não abriu mais".

A voz que age e nos fala das coisas que Rita fazia é a do autor-narrador: no Boca de Rua três categorias se mesclam, tendo nisso uma potente força de real. Autor é narrador que é, muitas vezes, personagem. Neste caso, a voz é externa e lembra da vida de Rita; em muitos momentos deixa claro o quão próximo esteve dela, como colega de jornal e de rua: sente saudades, junto com os membros do Boca de Rua e os vizinhos de praça (exemplos: "agora quem precisa de curativo no coração somos nós, seus colegas, pois sentimos muita saudade"; "foi muito difícil aceitar sua perda"). O texto é escrito na primeira pessoa do plural. "Nós" sentimos saudade. "Nossa" colega. Um "nós" que vive também a rua e suas intempéries e, com a morte sempre a alcance, ainda sente dor e a carrega dignamente.

Rita morava na Praça Garibaldi, tinha amizades no açougue e na esquina onde vendia os exemplares do Boca de Rua, no encontro da Avenida Venâncio Aires com a Rua José do 
Patrocínio. Contudo, a ação de Rita é sempre passada: sorria, trabalhava, tinha gostos estranhos; ela foi até mesmo modelo em propagandas nas janelas traseiras dos ônibus do transporte público de Porto Alegre. Tudo no passado porque, como é o destino de todos nós - porém, infelizmente, muito mais apressado no caso da população de rua - Rita faleceu. A isso, a narrativa culpa um "irônico" destino ("Por ironia do destino, a Rita morreu de tuberculose"), afinal a doença que causou sua morte foi exatamente o tema das propagandas que Rita estampava na traseira de ônibus. Ironia? Ora, sabe-se que a tuberculose é uma doença já controlável, com vacinas e tratamento disponível gratuitamente pelo SUS (Sistema Único de Saúde); não deveria mais levar a mortes. Contudo, tal informação não parece ser verdadeira para a população de rua: segundo o Ministério da Saúde, em média 4,5 mil pessoas morrem devido à tuberculose anualmente no Brasil. As causas, para além do sistema imunológico de cada um, têm raízes sociais, ligadas à pobreza e à má distribuição de renda: assim que a população de rua é a mais vulnerável, com o risco de adoecimento por tuberculose 56 vezes superior à média nacional ${ }^{9}$. Não nos parece caso de um destino "irônico", e sim um fruto da desigualdade social, crescente no modelo capitalista neoliberal vigente (FATHEUER et al, 2016), insustentável e mortífero. Desigualdade que não deixa Rita mais falar e nem cantar ou recitar poesias, ou mesmo reclamar e brigar: está morta, assassinada por uma invisibilidade imposta a quem é jogado às ruas.

\section{CONSIDERAÇÕES FINAIS}

O texto mostra as pessoas em situação de rua como dignas de lembrança, na figura de Rita, e dignas de sentir dor, na figura do narrador e dos colegas de jornal e de praça: o Boca de Rua reestabelece, à população de rua, o direito à memória, algo tão comumente - e violentamente, mesmo que em silêncio - retirado delas e deles (VIANA; MORIGI, 2018a), além de explicitar a relação profunda com as ruas, alcunha que carregam a todo o lado, o morar na rua. Como que em uma homenagem à sua vida singular, a narrativa desponta como exemplo marcante daquilo que pretendemos pontuar aqui: em reação a definidores primários (HALL et al, 1978), discurso imposto, vemos no Boca de Rua o registro de uma narrativa que envolve as tensões vividas por um grupo social no tecido urbano, composto por um conjunto de práticas cotidianas de dominação, exclusão e formas de resistência social.

A partir das vozes expressas nas narrativas, comumente jogadas à categoria do exótico, é possível visualizar como são construídas memórias no contexto urbano, ora traumáticas ora

\footnotetext{
9 Informações do Ministério da Saúde. Acesso em: 25/10/2018. Disponível em:
} http://portalms.saude.gov.br/saude-de-a-z/tuberculose 
resignadas, ou mesmo alegres e que se apropriam de forma única da cidade na qual, literalmente, vivem: o Jornal Boca de Rua é uma escritura que grita, expõe-nos seu Rosto (LÉVINAS, 1997a; 1997b; BUTLER, 2011), obriga-nos a escutar, na leitura, a precariedade dessas vidas. Tira-nos, se tanto ainda é possível, de um estado de complacência para com a violência imposta a quem vive nas ruas, os marginais, que têm suas histórias silenciadas e elas sim - invisíveis, posto que elas e eles estão aí, cotidianamente diante de nós, extremamente visíveis, desafiando-nos e explicitando a falência do sistema capitalista neoliberal global. 


\section{REFERENCIAS}

ALLES, Natália Ledur. Boca de Rua: representações sociais sobre população de rua em um jornal comunitário. Dissertação (mestrado em Comunicação e Informação). Universidade Federal do Rio Grande do Sul, 2010. Disponível em: http://www.lume.ufrgs.br/handle/10183/23018.

BARBOSA, Márcio Ferreira. Expreiência e narrativa. Salvador: EDUFBA, 2003.

BARTHES, Roland. Introdução à análise estrutural da narrativa. In: MENDONÇA, Antônio Sérgio Lima; NEVES, Luiz Felipe Baeta. Análise estrutural da narrativa: seleção de ensaios da revista "Communications". Editora Vozes: Petrópolis, RJ, 1976. p.45-67

BIRD, S. E.; DARNDENNE, R. W. Mito, registro e 'estórias': explorando as qualidades narrativas das notícias. In: TRAQUINA, N. (Org.). Jornalismo: questões, teorias e "estórias". Lisboa: Veg, 1999.

BUTLER, Judith. Vida precária. Contemporânea: dossiê diferenças e (des)igualdades, n.1, p.13-33, janeiro/junho, 2011.

2015.

Relatar a si mesmo: crítica da violência ética. Belo Horizonte: Autêntica Editora,

DELEUZE, Gilles. Lógica do sentido. São Paulo: Perspectiva, 1998.

DELEUZE, Gilles; GUATTARI, Félix. Mil platôs: capitalismo e esquizofrenia. Volume 1. Rio de Janeiro: Editora 34, 1995a.

DELEUZE, Gilles; GUATTARI, Félix. Mil platôs: capitalismo e esquizofrenia. Volume 2. Rio de Janeiro: Editora 34, 1995 b.

DERRIDA, Jacques. A escritura e a diferença. São Paulo: Perspectiva, 1995.

Gramatologia. São Paulo: Perspectiva, 2008.

ELIAS, Norbert. A sociedade de corte: investigação sobre a sociologia da realeza e da aristocracia de corte. Rio de Janeiro: Jorge Zahar Ed., 2001.

FATHEUER, Thomas; FUHR, Lili; Unmüßig. Crítica à economia verde. Rio de Janeiro: Fundação Heinrich Böll, 2016.

GREIMAS, Algirdas Julien.; FONTANILLE, Jacques. Semiótica das paixões. São Paulo: Editora Ática, 1993. 
HALL, Stuart; CRITCHER, Chas; JEFFERSON, Tony; CLARKE, John; ROBERTS, Brian. Policing the crisis: mugging, the State, and Law and Order. The Macmillan Press LTD: London, 1978.

LAGO, Cláudia. Ensinamentos antropológicos: a possibilidade do Outro no Jornalismo. Brazilian Journalism Research, vol.6, n.1. Sociedade Brasileira de Pesquisa em Jornalismo: 2010.

LATOUR, Bruno. Reagregando o social. Bauru, SP: EDUSC/ Salvador, BA: EDUFBA, 2012.

LEMOS, André. A comunicação das coisas: teoria ator-rede e cibercultura. São Paulo: Annablume, 2013.

LÉVINAS, Emmanuel. Entre nós: ensaios sobre a alteridade. Petrópolis, RJ: Editora Vozes, 1997a.

Descobrindo a existência com Husserl e Heidegger. Lisboa: Instituto Piaget, 1997b.

ORLANDI, Eni Puccinelli. As formas do silêncio no movimento dos sentidos. Campinas: Editora da UNICAMP, 1992.

Análise de discurso: princípios e procedimentos. Campinas: Pontes, 1999.

SANTELLA, Lucia; CARDOSO, Tarcísio. O desconcertante conceito de mediação técnica em Bruno Latour. Revista Matrizes, São Paulo, v.9, n.1, p.167-185, janeiro-julho, 2015.

SODRÉ, Muniz. A abominação do outro. In: GOBBI, Maria Cristina; HOHLFELDT, Antonio (orgs.). Teoria da Comunicação: antologia de pesquisadores brasileiros. Porto Alegre: Sulina, 2004.

TRAQUINA, Nelson. Teorias do Jornalismo: porque as notícias são como são. Florianópolis: Insular, 2004.

VIANA, Arthur; MORIGI, Valdir. Por um jornalismo humanizado: o silêncio sobre as mortes das mulheres e dos homens "infames" em Zero Hora. P2P \& Inovação, Rio de Janeiro: vol.4, n.2, p.53-69, março/agosto, 2018a.

Redes de desejos consonantes: a impossibilidade da polifasia cognitiva na era da pósvverdade. In: Revista Animus. Santa Maria: v. 17, p. 1-18-18, 2018b. A IM COVERDADE 